\title{
LOS PELIGROS DEL CAJÓN DE SASTRE. SENTENCIA DE NULIDAD POR FALTA DE FUNDAMENTACIÓN DE LAS CONCLUSIONES PROBATORIAS EN EL CASO TOCORNAL (CORTE SUPREMA)
}

\author{
Comentario de Daniela Accatino Scagliotti
}

Santiago, diecisiete de enero de dos mil siete.

VISTOS:

Por sentencia de trece de noviembre de dos mil seis, pronunciada en los antecedentes Rol Interno N²73-2006 y Rol Único Nº0600170079-9, del Tercer Tribunal de Juicio Oral en lo Penal de Santiago, integrado por las Juezas señoras Marcela Urrutia Cornejo, Doris Ocampo Méndez y Olga Fernández Berardi, se absolvió a JORGE ALBERTO TOCORNAL BABRA, 44 años, soltero, Sub Gerente de banco, cédula de identidad $\mathrm{N}^{\circ}$ 9.085.645-6, de la acusación formulada en su contra de ser autor de los delitos reiterados de abuso sexual en la persona de sus hijos menores Jorge y Joaquín ATP, ocurridos entre julio y noviembre de 2005 en la comuna de Vitacura de esta ciudad.

Asimismo se resolvió condenarlo, como autor de los siguientes ilícitos:

1.- Delito continuado de violación, en grado consumado, perpetrado entre julio y noviembre de 2005 en la persona de su hijo Joaquín ATP, previsto en el artículo 362 del Código Penal, a la pena de SIETE AÑOS de presidio mayor en su grado mínimo, inhabilitación absoluta perpetua para cargos y oficios públicos y derechos políticos y la inhabilitación absoluta para profesiones titulares mientras dure la condena.

2.- Delito continuado de abuso sexual, en grado consumado, cometido en la persona de sus hijos menores Jorge y Joaquín ATP, (ambos menores de 14 años), ocurridos entre julio y noviembre de 2005 en la comuna de Vitacura de esta ciudad, previstos en el artículo 366 quater del Código Penal, a la pena de CUATRO AÑOS de presidio menor en su grado máximo, accesoria de inhabilitación absoluta perpetua para derechos políticos y la de inhabilitación absoluta para cargos y oficios públicos durante el tiempo de la condena.

Se impone al condenado además, el pago de las costas de la causa, se le priva de la patria potestad o del derecho a obtenerla, se decreta su interdicción para ejercer la guarda y ser oído como pariente y se dispone su vigilancia por parte de la autoridad por los diez años siguientes al cumplimiento de la condena, sin concederle ninguno de los beneficios alternativos que contempla la Ley $\mathrm{N}^{\circ} 18.216 / 1983$, de 14 de mayo. 
En contra de esta resolución, la Defensa del sentenciado dedujo recurso de nulidad por las siguientes causales y con el carácter que a continuación se indica:

A) Causal principal, contenida en el artículo 373 letra a) del Código Procesal Penal, esto es, por infracción de Garantías, específicamente del principio de inocencia, lo que ocurre, en criterio del recurrente, como consecuencia de la inversión de la carga de la prueba, específicamente con la acreditación de la data de los hechos imputados, de elementos incriminatorios contra terceros sospechosos y del incidente formulado con ocasión de la liberación por el Ministerio Público de la Testigo Cecilia Pesce Ortega.

B) Causal conjunta con la que antecede, y que se funda en el artículo 373 letra a) del Código Procesal Penal, invocada como vulneración del Debido Proceso, consagrado en el artículo $19 \mathrm{~N}^{\circ} 3$ inciso $5^{\circ}$ de la Constitución Política de la República, la que se habría producido con motivo de la investigación de los hechos por parte del Ministerio Público, acusada como imperfecta y con omisión de diligencias relevantes relacionadas con la indagación en torno a la participación de terceros.

C) Causal Subsidiaria, por infracción del artículo 374 letra e) del Código Procesal Penal, lo que habría acontecido por omisión en la sentencia del requisito del artículo 342 letra c), en relación con el artículo 297, del mismo cuerpo de ley.

D) Causal Subsidiaria, sustentada en la vulneración del artículo 374 letra a) del Código Procesal Penal, a cuyos efectos se estima que la sentencia ha sido dictada por tribunal incompetente, lo que ocurre considerando lo dispuesto en el artículo 484 del Código Procesal Penal y la disposición octava transitoria de la Constitución Política de la República en cuanto a que la fecha inicial de los supuestos delitos es anterior al 16 de junio de 2005, fecha de inicio de la reforma procesal penal en Santiago.

Declarado admisible el señalado recurso, por las causales precitadas, se fijó día y hora para la audiencia de rigor, la que tuvo lugar el 28 de diciembre de 2006, con la asistencia de los señores Fiscal, Querellante y Defensor, fijándose fecha para la comunicación de la sentencia el 17 de enero de 2007, a las 13:00 horas.

\section{CONSIDERANDO:}

A) Causal principal. 373 letra a) del Código Procesal Penal. Infracción de Garantías. Principio de Inocencia. Inversión de la carga de la prueba.

PRIMERO: Que, la primera causal en que se funda el presente arbitrio, encuentra, a criterio del recurrente, sustento en el artículo 373 a) del Código Procesal Penal, en razón de la vulneración del principio de inocencia que ampara al acusado y que se pretende infringido en este caso.

SEGUNDO: Que, tal razonamiento se construye en base de la tesis según el cual el tribunal pone de cargo de la defensa acreditar la data de las lesiones sufridas por uno de los menores víctima, lo que importa en su concepto alterar el peso de la prueba, en 
términos que la falta de acreditación originó la condena de su representado. Asimismo, sostiene que la deficiente investigación del Ministerio Público -apartada de las normas legales y con omisión de diligencias importantes, especialmente en relación con la incriminación de hechos respecto de terceros no indagados- afectó la garantía señalada, la que asimismo resulta vulnerada como consecuencia del rechazo del incidente formulado por su parte con ocasión de la liberación por el Ministerio Público de una testigo de relevancia. Todo lo anterior, estima, incide en el estándar de convicción que deben adquirir los sentenciadores, desde que este principio de inocencia es el que hace operativo el límite de convicción que está dado por la duda razonable.

TERCERO: Que, al respecto, cabe acotar que el reconocimiento expreso-como principio estructural de todo sistema de enjuiciamiento criminal moderno, y que determina su funcionalidad tanto en lo formal como en aspectos sustantivos, como asimismo su adecuada inserción y aceptación en el marco jurídico general de respeto a las garantías y derechos de las personas- está dado por admitir y velar por la eficaz y efectiva aplicación del mismo en el caso concreto, lo que importa aceptar que nadie -y en tanto no se hubiere dictado sentencia ejecutoriada en su contra, con los resguardos jurídicos de un debido proceso- puede ser estimado culpable de un delito, ni tratado como tal.

Que sólo con dicho proceder, y en mérito de tal acto jurisdiccional, como es la sentencia, es posible asegurar las garantías de un debido proceso.

CUARTO: Que, en lo substantivo, la necesaria acreditación por parte del Ministerio Público de todos los presupuestos fácticos que sirven de fundamento a su acusación, tanto los que dicen relación con el hecho punible materia de ella, sus circunstancias y las que determinan la participación culpable del imputado, en un justo y racional procedimiento, deberán emanar necesaria e ineludiblemente de la prueba producida en la audiencia del juicio oral, la que en su formulación ha de ajustarse a los principios de publicidad, contradicción e inmediación, conforme a la cual los sentenciadores deberán formar su convicción, en los términos exigidos por el artículo 297 del Código Procesal Penal.

QUINTO: Que, en tal desarrollo, sin perjuicio de lo señalado, y atendido que la necesidad probatoria se plantea como un proceso dinámico, resultante de las diversas formas que pueda asumir la defensa, y que determinarán o impondrán según el caso el despliegue de alguna actividad en tal sentido, particularmente cuando frente a los reproches del Ministerio Público se formule alguna tesis o teoría alternativa de aquélla, caso en el cual será de su cargo acreditarla, sin que por ello se pueda sostener que se afecte el debido proceso o el carácter de inocente del acusado, ya que como se ha venido diciendo la convicción de los jueces, ya para acoger la acusación, ya para desestimarla, ya para admitir los planteamientos alternativos de la defensa, deberá ser consecuencia de la acreditación de los mismos mediante la prueba producida en la audiencia. 
SEXTO: Que, así las cosas, y en relación con el motivo de nulidad que nos convoca, no puede sostenerse que los argumentos que ha planteado el recurrente -ya en relación con el establecimiento de la data de las lesiones sufridas por el menor Joaquín ATP, cuya precisión o fecha no fue establecida sino entre dos rangos de tiempo, entre los cuales se habría producido la agresión sexual a dicho menor, situación que por lo demás llevó a los jueces a calificar el delito como continuado considerando la ocurrencia de las conductas imputadas, ni aquello que no resulta ser materia de la acusación fiscal como es la intervención de terceros en los hechos, cuestión introducida al proceso por la defensa, como lo relacionado con el rechazo de una incidencia durante la audiencia relativa a la liberación de una testigo por parte de la fiscalía- como lo pretende el señor defensor, importen o conlleven alterar la carga de la prueba y con ello concluir que se lesiona el principio de inocencia. Cabe tener presente al efecto, que tal acontecer no ha importado liberar al órgano persecutor de acreditar sus pretensiones, como tampoco imponer a la defensa la prueba de cargos, ya que el establecimiento de los presupuestos que introdujo esta última al juicio, y que pudieren haber sido de mérito para generar alguna duda razonable en los sentenciadores en términos que los determinara a resolver de una manera diferente a como lo han hecho, no importan la vulneración que por esta causal ha sido formulada, considerando que la valoración emana, por cierto, de la prueba aportada al juicio.

SÉPTIMO: Que, por lo expuesto, consecuencialmente no se acogerá la presente causal.

B) Causal principal conjunta. 373 letra a) del Código Procesal Penal por vulneración del Debido Proceso.

OCTAVO: Que, el segundo motivo en que se funda este arbitrio y que se ha formulado conjuntamente con el principal, se sustenta en el artículo 373 letra a) del Código Procesal Penal, cuya trasgresión se habría producido por vulneración de la Garantía del Debido Proceso, establecida en el artículo $19 \mathrm{~N}^{\circ} 3$ inciso $5^{\circ}$ de la Constitución Política de la República, como consecuencia de la deficiente investigación desarrollada por el órgano persecutor en cuanto imperfecta y no ajustada al estándar legalmente exigible.

NOVENO: Que, de lo expuesto es claro que el vicio que sirve de soporte al presente recurso, se relaciona con la "calidad" de la investigación del Ministerio Público, órgano a quien por imperativo del artículo 83 de la Constitución Política de la República le corresponde de manera exclusiva la investigación y el ejercicio de la acción penal, actividad que ha sido reglamentada en el Código Procesal Penal, y sujeta a los controles que la misma ley establece, como son aquellos dados al Juez de Garantía, al imputado y demás intervinientes. De tal manera que, aún hipotética o especulativamente, para el caso de ser efectiva la afirmación de la Defensa, en cuanto a las deficiencias, infracciones y omisiones que ha señalado, ellas debieron ser materia de reclamación en la oportunidad correspondiente, es decir durante el curso de dicha investigación y aún en la etapa de preparación de juicio oral, por vía de exclusión de prueba, por lo que, al no 
hacerlo, los reproches en que busca asilo, resultan improcedentes, y no pueden servir de fundamento al presente recurso.

Que en todo caso, lo sostenido es sin perjuicio de la valoración que de los antecedentes de prueba aportados al juicio en cuestión y en su caso, pudieron hacer los jueces del tribunal de Juicio Oral, ya para dar mérito a las pruebas aportadas, o bien para desmerecerlas en razón de su génesis contraria a las normas legales o constitucionales que reglan la labor del Ministerio Público, única formula que resulta procedente en dicho estadio procesal y que se comprenden en las facultades de los Jueces de este último Tribunal.

DÉCIMO: Que, acorde a lo razonado, no se hará lugar al acogimiento del recurso interpuesto por este motivo.

C) Causal subsidiaria. Infracción del artículo 374 letra e) del Código Procesal Penal, en relación con los artículos 342 letra c) y 297, todos de este mismo cuerpo de ley.

UNDÉCIMO: Que la tercera causal, planteada como subsidiaria de las precedentemente referidas, encuentra anclaje en el artículo 374 letra e) del Código Procesal Penal, la que al decir del recurrente, se ha configurado por omisión en la sentencia del requisito del artículo 342 letra c), en relación con el artículo 297, del mismo cuerpo legal, en razón de sobrepasar dicha resolución los límites de la libre valoración de la prueba, al no contener una exposición clara, lógica y completa, no sólo de los hechos y circunstancias de la causa, sino también de aquellos que dicen relación con la valoración de los medios de prueba en que se fundamentan sus conclusiones, lo que determina en definitiva que el fallo recurrido arribara a juicios parciales y equivocados.

DUODÉCIMO: Que, es menester dejar sentado que el régimen probatorio adoptado en el nuevo sistema y que comprende por una parte la libertad de prueba y por la otra, la libre valoración de la misma - dos aspectos indispensables para su adecuada funcionalidad- no puede sino tener otros límites que los expresamente dados por el legislador, cuales lo son, la lógica, las máximas de la experiencia y los conocimientos científicamente afianzados, todo lo cual ha de materializarse en la fundamentación de las decisiones judiciales, de tal forma que estas guarden la correspondiente armonía con los extremos señalados, en términos de satisfacer los fines del proceso, manera en que se legitiman las resoluciones judiciales, particularmente aquellas contenidas en una sentencia definitiva, en el contexto de la seguridad jurídica y de la paz social.

DÉCIMO TERCERO: Que, en dicho mérito, y del tenor del extenso fallo que ha precedido a la decisión de los sentenciadores, quienes incluso, como plus han trascrito las diversas actuaciones llevadas a efecto en la audiencia, sin que ello sea una exigencia de las estrictamente necesarias que señala el artículo 342 del Código Procesal Penal -es sólo a partir de la motivación decimotercera, donde se da inicio al análisis de la prueba 
que han percibido por sus sentidos y que en dicho contexto les corresponde exclusivamente ponderar- arriban a la conclusión que en relación con la acusación Fiscal relativa a los delitos de violación del menor Jorge ATP y de abuso sexual de los menores Jorge y Joaquín ATP, se habrían acreditado tanto aquellos como estos, así como la participación que en calidad de autor ha correspondido en ellos al imputado.

DÉCIMO CUARTO: Que, sin embargo, tales consideraciones no se ajustan al raciocinio propio del marco legal a la hora de arribar a la decisión condenatoria, ya que está afectado el mecanismo de la lógica con que se ha debido obrar en relación a los tópicos que se han planteado en el recurso por esta causal, ya para acoger la prueba de la fiscalía, ya para desestimar aquella aportada por la defensa, como al referirse a los hechos no probados de la causa en relación con tales ilícitos.

DÉCIMO QUINTO: Que, en efecto y como se ha advertido en el libelo, la existencia de aparentes discrepancias entre los informes periciales producidos en la causa, en cuanto a la fecha y naturaleza de las lesiones que han sido advertidas en el menor, no han sido obstáculo para tener por sentada su naturaleza y origen, lo que sin embargo, ha ocurrido sin que los jueces expliquen o den razón de tal proceder, omisión que importa transgredir el precepto del artículo 342 letra c) del Código Procesal Penal, sin que pueda sostenerse como lo pretende Fiscalía, que por tratarse de una cuestión accesoria o inexistente, sea suficiente para subsanarla y despejar las dudas que al respecto se plantean, más aun cuando tales afirmaciones deben provenir precisamente del Tribunal y no de las partes del juicio.

DÉCIMO SEXTO: Que, del mismo modo y para cumplir los fines de fundamentación del fallo, particularmente aquel que permita reproducir de forma clara y precisar el razonamiento de los sentenciadores, no concurre, a la hora de decidir, cuál es la data de las lesiones, las razones por las cuales no fue posible determinar le fecha en que ocurrieron, ya sean estas positivas o negativas, y las consecuencias, si alguna tuviere, en la decisión definitiva y en relación con los planteamientos de la defensa. Más aún cuando en base a dicha indeterminación se llegó a concluir que los delitos acreditados tenían el carácter de continuados, sin que, y por las mismas razones, se satisfagan las exigencias doctrinarias dadas para tal figura, de lo que resulta que el lógico encadenamiento de pruebas, valoración de la misma, hechos probados o no probados, y conclusiones, en la especie no resulta de una secuencia correlativa de etapas, o procesos ya materiales, ya intelectuales, lo que impide, como se ha anticipado, satisfacer los requerimientos perentorios de la norma del artículo 342 letra c) y en relación con el artículo 297, ambas del Código Procesal Penal.

DÉCIMO SÉPTIMO: Que, las anteriores reflexiones son igualmente aplicables al planteamiento que formula el recurrente en relación con las conclusiones inconsultas que se han derivado de las exposiciones de los peritos Marlene Martínez y Digadiel Rojas, en cuanto a ciertas características del imputado, por lo que las mismas, sin el idóneo 
sustento, impide a los jueces arribar a ellas, ya sea por carecer de tales conocimientos, ya por no existir antecedentes de tal naturaleza que la determinen.

DÉCIMO OCTAVO: Que, por lo demás y a mayor abundamiento, cabe señalar que la forma general como el Tribunal ha procedido para rechazar la prueba documental producida en la causa, sin perjuicio de la nominación que en cada caso y respecto de los instrumentos en cuestión se ha dado, resulta del todo insuficiente ya para atribuirle mérito o bien restárselo sin siquiera ilustrar o precisar el porqué ellos no son significativos o no aportan elementos de juicio a la hora de su ponderación.

DÉCIMO NOVENO: Que, conforme lo dicho, el presente recurso será acogido por esta causal en análisis, resultando por consiguiente innecesario pronunciarse por el motivo cuarto de nulidad, esto es la causal subsidiaria que se funda en el artículo 374 letra A) del Código Procesal Penal.

Y visto lo dispuesto en los artículos 297, 342, 372, 374 letra e), 376, 383, 384, 386 del Código Procesal Penal, se acoge el recurso, de nulidad deducido por la Defensa del imputado Jorge Alberto Tocornal Babra, por la causal tercera subsidiaria, esto es, la del artículo 374 letra e) del Código Procesal Penal, declarándose por consiguiente la nulidad del juicio y de la sentencia de tres de noviembre de dos mil seis, dictada en estos antecedentes por la Tercera Sala del Tribunal de Juicio Oral en lo Penal de Santiago, debiendo procederse a realizar un nuevo juicio ante tribunal no inhabilitado.

Acordada con el voto en contra de abogado integrante Sr. Domingo Hernández E., quien estuvo por rechazar el recurso en estudio por todas las causales formuladas, en atención a las siguientes consideraciones:

1. Que en lo que dice relación con los dos primeros motivos de invalidación que se han esgrimido, comparte los fundamentos dados en la presente sentencia y los hace suyos.

2 Que en lo concerniente a la causal tercera subsidiaria y que dice relación con la infracción al artículo 342 letra c) en relación al artículo 297 del Código Procesal Penal, la que se fundamenta en el motivo de nulidad que contempla el artículo 374 letra e) del señalado cuerpo legal, estima que los planteamientos del recurrente sólo dicen relación con una diversa valoración de la prueba aportada al proceso, cuya ponderación, por ser de la esencia de la potestad jurisdiccional, compete de manera exclusiva a los jueces de la causa, toda vez que, y en razón de los principios de la inmediación, contradicción y oralidad, sólo estos se encuentran en situación de aquilatarla.

3. Que, en tal contexto, la diversa apreciación que de la prueba rendida tuviere el recurrente, no puede servir de fundamento a un recurso de carácter extraordinario y estricto como el que se analiza, más aún cuando de su exposición no aparece que se hubiere incurrido en los vicios que se denuncian.

En efecto, del examen del fallo impugnado se desprende que los jueces se han hecho cargo de la prueba rendida, dando en cada caso los fundamentos que permiten claramente comprender las razones por las cuales fue admitida o rechazada, 
exponiendo igualmente y de manera lógica las consideraciones que en virtud de ella les fue posible arribar para el establecimiento de los hechos que tuvieron por sentados, los que por reunir en su caso las exigencias típicas, pudieron ser calificados acorde con los delitos que establecen y sancionan los artículos 362 y 366 quarter del Código Penal, de tal suerte que no surge ninguna duda en cuanto a que la sentencia en cuestión cumple a cabalidad con los requisitos del artículo 342, letra c), sin que los extremos probatorios dados por el artículo 297 del Código Procesal Penal, hubieren sido sobrepasados, desde que no se advierte, más aún ni el recurrente lo señala, cuál es el principio de la lógica contrariado, ni los conocimientos científicos transgredidos, menos aún se refiere el recurso a las máximas de la experiencia, sin que la sola mención genérica de estos elementos inherentes a la sana crítica, sin la debida especificación en cada caso, pueda revestir mérito suficiente para configurar un vicio de nulidad, con las consecuencias que de ello deriva, particularmente en el caso de autos, desde que la anulación del fallo conlleva la realización de un nuevo juicio y, por consiguiente, una nueva exposición de las víctimas de corta edad, a los trámites y tensiones que eso significa, por lo que el rigor en el análisis de la causal invocada y el imperativo de no desvirtuar el sentido y alcance de este arbitrio, llevan a este disidente a rechazar la presente causal de invalidación.

4. Que, por último, y en relación con la causal del artículo 374 letra A del Código Procesal Penal, y dado que es un hecho de la causa que los sucesos acontecieron entre julio y noviembre de dos mil cinco, fecha en la que se encontraba plenamente vigente en la región metropolitana la novel justicia penal, el conocimiento de estos antecedentes ha sido sometido y resuelto por el tribunal que conforme a la ley, naturalmente era llamado a ello, por lo que en la especie no se configure el vicio que por esta causal se ha reclamado.

5. Que, por lo expuesto, estuvo por rechazar el recurso en todas sus partes y, en consecuencia, declarar que el juicio oral de autos, así como la sentencia de trece de noviembre de dos mil seis, pronunciada por la Tercera Sala del Tribunal del Juicio Oral en lo Penal de Santiago, no son nulos.

Redacción del Abogado Integrante señor Juan Carlos Cárcamo Olmos y del voto disidente su autor.

Regístrese y devuélvase.

Rol N6112-06.

Pronunciado por la Segunda Sala integrada por los Ministros Sres. Alberto Chaigneau del C., Rubén Ballesteros C., Hugo Dolmestch U. y los abogados integrantes Sres. Juan Carlos Cárcamo O. y Domingo Hernández E.

Autoriza el Secretario de esta Corte Suprema don Carlos Meneses Pizarro. 


\section{COMENTARIO}

Entre las causales de nulidad previstas por el Código Procesal Penal (CPP), hay una que es invocada con mucha frecuencia por los recurrentes, a veces como causal principal, pero sobre todo -como ocurre en el caso que es objeto de este comentario-como causal conjunta o subsidiaria. Se trata de la omisión de alguno de los requisitos de la sentencia previstos por el artículo 342, letras c), d) y e) del CPP. En particular, se suele impugnar por esta vía la fundamentación de las conclusiones probatorias, reprochándola como insuficiente o defectuosa a la luz de las exigencias establecidas en el artículo 297 CPP, que, como se sabe, sujeta la valoración de la prueba a los principios de la lógica, las máximas de la experiencia y los conocimientos científicamente afianzados y requiere, además, que la fundamentación de esa valoración sea completa -que se refiera a toda la prueba producida y a todos los hechos y circunstancia que se den por acreditados- y permita al lector arribar a las mismas conclusiones afirmadas en la sentencia. ${ }^{1}$

Esta tendencia puede ser interpretada de dos formas. O bien los Tribunales de Juicio Oral en lo Penal (en adelante TJOP) no están justificando, en general, adecuadamente las conclusiones probatorias que afirman en sus sentencias, o bien la causal apuntada es vista como un cajón de sastre en el que, con buena voluntad y algo de maña, todo puede caber. Cualquiera sea el caso, la tarea de las Cortes de Apelaciones y la Corte Suprema al enfrentarse a esa causal de nulidad es delicada y crucial.

En el marco del sistema restrictivo de recursos establecido por el Código Procesal Penal, la causal en cuestión constituye la vía fundamental de control de la racionalidad en el establecimiento judicial de los hechos. El razonable ejercicio de ese control supone, sin embargo, una tarea ciertamente difícil: la de trazar la frontera entre una motivación completa y adecuada y una insuficiente o defectuosa. A pesar de su dificultad es indispensable abordarla y no ceder a dos tentaciones que parecen permitir eludirla. La primera es la tentación formalista, que restringe la aplicación de la causal a los casos fáciles de ausencia de consideraciones o argumentos contradictorios. Su debilidad reside en dejar abierto el paso a arbitrariedades menos evidentes. ${ }^{2}$ La segunda tentación es la vulgarista, que recurre a la causal laxamente, sin hacer esfuerzos por articular criterios que precisen, en diversas clases de situaciones probatorias, el sentido y el alcance de las exigencias del artículo 297. El primer peligro que esta segunda tentación envuelve es, de nuevo, la arbitrariedad, referida ahora a la obtención de la nulidad y el acceso a un nuevo juicio. Si se invocan los "principios de la lógica", las "máximas de la experiencia"

\footnotetext{
${ }^{1}$ Alguna información estadística relevante puede encontrarse en Chaigneau, A., "Tabla detallada de resúmenes de recursos de nulidad presentados ante la Corte Suprema entre 2000 y 2005", Política Criminal, $\mathrm{N}^{\mathrm{o}}$ 2, 2006. D2, pp. 1-26.

${ }^{2}$ Esa interpretación vuelve más áspera además la tensión entre el CPP y los tratados internacionales suscritos por Chile que reconocen un derecho a favor de quien ha sido condenado penalmente para interponer un recurso ante un tribunal jerárquicamente superior. Vid. al respecto Coloma, R., "Los límites del recurso de nulidad como mecanismo de control de la decisión sobre los hechos", en Revista de Derecho de la Universidad Católica de Temuco, No III, 2002, pp. 55-77.
} 
o los "conocimientos científicamente afianzados" sin realizar un esfuerzo argumentativo para diferenciar sus condiciones de aplicación y establecer el nexo entre el concepto y la solución supuestamente justificada en él, las partes y el público pueden preguntarse entonces, legítimamente, si no habrá sido la alta exposición pública de un caso, o la posición social del imputado, lo que determinó que cierta sentencia y cierto juicio "merecieran" ser anulados. Por otra parte, si la casual de falta de fundamentación se usa como un flexible cajón de sastre al que recurrir cuando, por cualquier consideración, la sentencia y el juicio "merezcan" ser anulados, la nulidad perderá el carácter extraordinario y estricto que tiene en el nuevo diseño procesal penal y se derrochará injustificadamente el enorme esfuerzo institucional y personal (sobre todo si hay víctimas menores de edad) que significa la repetición de un juicio. ${ }^{3}$

La sentencia de la Corte Suprema que es objeto de este comentario constituye un buen ejemplo de la seducción que la tentación vulgarista parece ejercer sobre nuestros tribunales superiores. ${ }^{4}$ Así, el fundamento de la anulación es, según el considerando décimo cuarto, "que está afectado el mecanismo de la lógica con que se ha debido obrar", exigencia de la que no se esboza ninguna caracterización general que permita apreciar su infracción en el caso concreto. La estrategia elusiva que la sentencia sigue consiste en identificar las partes de la sentencia anulada que pondrían de manifiesto ese evidente defecto. El problema es que si miramos la sentencia en cuestión (Sentencia de 13 de noviembre de 2006 del Tercer TOJP de Santiago), sus posibles insuficiencias no resultan en absoluto lo evidentes que los argumentos del voto de mayoría de la Segunda Sala de la Corte Suprema pretenden. Puesto que la sentencia del TOJP es extensísima (más de doscientas páginas) sólo transcribiré a continuación algunos párrafos que permiten poner de manifiesto la observación anterior.

La primera ilustración de la afección del "mecanismo de la lógica” sería, según el considerando décimo quinto, el haber tenido por acreditada la naturaleza y origen de las lesiones del menor a pesar de haber "aparentes discrepancias entre los informes periciales producidos en la causa", "sin que los jueces expliquen o den razón de tal proceder". Con todo, en el considerando vigésimo de la sentencia anulada nos encontramos con las siguientes declaraciones:

"Que en sus alegatos de apertura y clausura la defensa arguyó, en primer término, que los hechos que se imputan a Tocornal no se cometieron, no ocurrieron nunca porque no hay indicadores de penetración anal. Para tal efecto presentó a dos peritos, Carmen Cerda y Luis Ravanal, que periciaron el informe que elaboró el Médico Legista del Servicio Médico Legal Ricardo Díaz Serani. Ambos peritos de la defensa

\footnotetext{
${ }^{3}$ Un esfuerzo malgastado que, por otra parte, implica, en nuestro sistema procesal penal, el riesgo para el condenado en el primer juicio de terminar sometido a una pena más alta en el segundo. Esto es precisamente lo que ocurrió en el caso que motiva este comentario.

${ }^{4}$ Lo que no excluye, cabe advertir, que la tentación formalista no resulte igualmente sugestiva. Vid. al respecto mi trabajo "La fundamentación de la declaración de hechos probados en el nuevo proceso penal. Un diagnóstico”, en Revista de Derecho, Universidad Austral de Chile, Vol. XIX, No 2, 2006, p. 15 y nota 13.
} 
criticaron la simpleza y falta de descripción del informe de aquel, expresando que éste no permitía a otros peritos concluir lo que en él se contenía, esto es, que las supuestas lesiones eran compatibles con el relato del menor.

Que las declaraciones de Cerda y Ravanal serán desestimadas por el tribunal primero, porque nunca examinaron al menor, y porque sus dichos estuvieron referidos a un informe escrito, que no fue la prueba rendida en este juicio oral toda vez que aquella estuvo constituida por la declaración que el perito Díaz Serani prestó en audiencia y a través de la cual, durante el interrogatorio y contrainterrogatorio, ilustró al tribunal acerca de las lesiones, zonas blanquecinas, fisuras e hipotonía que presentaba el ano del niño XX.

“Asimismo, la afirmación de la defensa durante la clausura de que las declaraciones de estos peritos se encuentran documentadas será desestimada habida cuenta de los principios y normas de la reforma procesal penal, en virtud de los cuales la prueba a valorar es la que se rinde en el juicio oral, sin que sea posible que los sentenciadores revisen la carpeta de la fiscalía o los informes escritos que se contienen en ella.

No dejó de llamar la atención de estos sentenciadores que ambos peritos -Cerda y Ravanal- se hubiesen limitado a criticar el informe escrito que Díaz Serani que le era desfavorable a la defensa, pero nada dijeron del de YY [el otro menor], que les era propicio.

Asimismo, en cuanto al cuestionamiento de la especialidad del perito Díaz Serani, el tribunal no la considera, porque este médico se desempeña en el Servicio Médico Legal, efectuando alrededor de 60 pericias al mes relativas a delitos sexuales, en cambio la perito Cerda está a cargo de la cátedra de Medicina Legal de la Universidad de Chile y el doctor Luis Ravanal trabajó en el Servicio Médico Legal como jefe de Tanatología.

Especial detención merece una de las afirmaciones de la perito Cerda Aguilar, la cual, para cuestionar la experticia de Díaz Serani, refirió que en sus 30 años de experiencia nunca había visto heridas o fisuras que no fueran a las 6 de la tarde, en posición cúbito abdominal o mahometana, dando una explicación médica al respecto, pero que se contradice con jurisprudencia existente en materia de violaciones por vía anal.

[...] [Se citan tres fallos]

Que para desacreditar el testimonio de Díaz Serani, en lo que atañe a cómo se realizan las pericias de sexología y quien practica la anamnesis de las víctimas, la defensa presentó como testigo a Marisol Barra, auxiliar de paramédico en sexología del Servicio Médico Legal. Su testimonio resultó infructuoso, toda vez que no recordó las actividades que realizó el día dos de diciembre del 2005, como tampoco haber atendido a un menor ese día. Sus asertos referidos a las labores que desempeña no pudieron contradecir a las del doctor Díaz Serani, contrariamente a lo afirmado por la defensa en su clausura, toda vez que expresó trabajar con un grupo de médicos y conocer al doctor Díaz Serani, sin que se precisara si ese día trabajó con aquel”. 
Como se puede apreciar, la parte transcrita de la sentencia del TJOP no omite justificar la desestimación de los informes periciales aportados por la defensa, como parece sugerir la sentencia de la Corte Suprema, sino que, por el contrario, aporta argumentos claramente dirigidos a ese fin. Para fundar la decisión de anular en esta parte de la sentencia del TJOP habría sido necesario afirmar y justificar el carácter defectuoso o insuficiente de esos argumentos. Algo que la sentencia de nulidad no hace (incurriendo, ella sí, por tanto, en una infracción de la exigencia de fundamentación).

Algo semejante ocurre con el segundo de los puntos en los que la sentencia anulada resultaría defectuosa. De acuerdo al considerando décimo sexto de la sentencia de nulidad aquélla omite indicar la data de las lesiones o las razones por las que no fue posible determinarla y las consecuencias que ello pudiera tener en la decisión definitiva. La lectura del fallo anulado resulta, también en esta ocasión, desconcertante. Por una parte, el considerando décimo sexto precisa que:

“(...) resultó acreditado que un adulto, accedió carnalmente por vía anal, en distintas oportunidades, a un menor de 14 años de edad, vulnerando la misma norma prohibitiva, y efectuando las conductas ilícitas respecto del mismo sujeto pasivo, pero al no haberse podido determinar el número de veces, ni fechas en que se realizaron dentro de ese período, se sancionarán como un delito continuado”.

Previamente, en el considerando décimo tercero la sentencia da cuenta de las razones que permiten arribar, a partir de la prueba aportada en juicio, a esas conclusiones y argumenta latamente sobre la credibilidad de las declaraciones de la víctima y de los testigos de oídas y sobre su confirmación con las declaraciones de los peritos. Unas y otras se reproducen además, in extenso, en el considerando octavo de la sentencia y en ellas - particularmente en la declaración del médico legista Jorge Díaz Serani- se hace expresa referencia a la imposibilidad de determinar la fecha exacta de las lesiones.

Por último, en el considerando vigésimo quinto la sentencia anulada vuelve a referirse a la cuestión de la indeterminación de las fechas en que se habrían cometido los ilícitos y justifica de qué manera incide esa indeterminación en la decisión que adopta en definitiva el Tribunal:

“ (...) En cuanto a la pluralidad de acciones, existieron conductas similares entre sí, ocurridas en distintas fechas, las que no fueron posibles determinar con certeza en atención a que sólo se contó con la versión de las víctimas, ambos niños pequeños que se referían en plural, a que estos sucesos ocurrían cuando salían con el padre durante las visitas reguladas. Esta información no se desprendió indubitadamente de la prueba aportada, no se pudo determinar los fines de semana que estuvieron con el padre, y sólo se acreditó que estos eventos ocurrieron más de una vez en el lapso estimado como aproximado, en sus dos vértices de inicio y fin, lo que constituye el transcurso de cierto lapso de tiempo entre la ejecución de cada una de las acciones; todas estas acciones ilícitas se efectuaron en perjuicio de los mismos ofendidos, 
dándose en consecuencia la unidad de sujetos pasivos, en cada caso, como asimismo, que en cada uno de ellos, se vulneraron las mismas normas punitivas.

Desde esta perspectiva, los hechos establecidos en los motivos respectivos, constituyen un conjunto de conductas ilícitas de un mismo sujeto, ejecutadas con el mismo propósito, en contra de los mismos afectados, dentro de un mismo contexto y en un lapso de tiempo determinado, en la especie, entre los meses de julio y noviembre del 2005, y que vulneraron el mismo bien jurídico protegido, la indemnidad sexual de los menores afectados, sin que se pueda precisar con certeza el número de ellas ni las fechas en que se realizaron, en consecuencia, sólo cabe aplicar esta figura denominada delito continuado, sancionando los diversos hechos como un solo delito, en cada caso, y esta falta de certeza, sobre la cual se ha razonado en forma lata, es el fundamento que impulsa la consecuente penalidad más baja”.

Por consiguiente, la pretendida omisión de argumentos, denunciada en la sentencia de nulidad, no parece corresponder tampoco en esta parte a la realidad de la sentencia anulada. También aquí la impugnación habría debido fundarse en el carácter insuficiente o defectuoso del razonamiento desarrollado en la sentencia anulada. O bien, si el problema fuera -como confusamente sugiere el considerando décimo sexto de la sentencia de la Corte Suprema- la falta de satisfacción de las exigencias doctrinales de la figura del delito continuado, la impugnación habría debido fundarse entonces en la existencia de una errónea aplicación de derecho (artículo 373 letra b del CPP), causal que no fue invocada por la defensa al deducir el recurso.

La perplejidad continúa con respecto al tercer punto que demostraría que en la sentencia anulada "está afectado el mecanismo de la lógica con que se ha debido obrar". Se trata, como denuncia el considerando décimo séptimo de la sentencia de nulidad, de la falta de sustento de las "conclusiones inconsultas que se han derivado de las exposiciones los peritos Marlene Martínez y Digadiel Rojas, en cuanto a ciertas características del imputado". Esas conclusiones serían, al parecer, las que formula la sentencia anulada en el considerando vigésimo segundo, en él se ocupa de justificar la desestimación de las alegaciones del imputado, evaluando su credibilidad. En ese contexto se señala que:

"Su frialdad, evidenciada por la psiquiatra Marlene Martínez y el psicólogo Digadiel Rojas fue observada por estas jueces, aún cuando habían transcurrido casi nueve meses después de esas evaluaciones, manteniendo el mismo desafecto y distancia afectiva que los peritos percibieron".

Estas conclusiones carecerían de sustento en la sentencia de juicio oral si en ella no se hiciera referencia al contenido de las declaraciones de los peritos o si éstas no hicieran alusión alguna al punto en cuestión. Sin embargo, en el considerando octavo se reproducen las declaraciones de los peritos y en ambas hay referencias claras a la "frialdad" del imputado: 
"En todo su relato respecto de la familia hay poca modulación afectiva, esto significa que es concordante con los contenidos pero lo hace con poca modulación, hay carencia de emoción, uno esperaría que si habla del hijo y de los problemas de salud de este que hubiera sintonía, manifestaciones personales y en eso se ve frío como si tuviera alejado de la situación, cuando habla de su hijo o de su ex esposa pareciera que habla de otras personas. Esto tiene que ver con la empatía”. [Declaración de Marlene Martínez]

"Explica que tampoco se advierte un correlato afectivo en su narración, se observa distancia afectiva con lo que relata. (...) También, explica, evidencia distancia emocional o frialdad afectiva, hace alusión a los hechos con distancia y devaluando al hijo, lo describe como un problema, enfermo, no hay ni siquiera afecto depresivo, esto se advierte, dice, tanto en la clínica como en el test”. [Declaración de Digadiel Rojas]

De nuevo, entonces, si se toma en cuenta la sentencia anulada en su totalidad, el defecto imputado no resulta en absoluto evidente. Parece tratarse además, en este caso, de un eventual defecto relativo a un punto de relevancia bastante menor en el conjunto de la justificación de la condena, al que difícilmente podría atribuirse influencia en al parte dispositiva de la sentencia, como requiere el artículo 375 del CPP para que proceda la declaración de nulidad.

Finalmente, la impugnación que la sentencia de la Corte Suprema hace de la forma en que la sentencia anulada desestima la prueba documental presenta problemas semejantes a los antes descritos. A diferencia de lo que ocurre con los anteriores argumentos, en este último se reconoce que el defecto no consiste en la falta de argumentos sino en su insuficiencia. Con todo, considerando que son muchos los documentos que la sentencia de juicio oral individualiza y desestima, la referencia genérica a su insuficiencia no parece-paradójicamente-suficiente. De hecho, hay casos en los que la insuficiencia de la justificación de la desestimación no resulta en absoluto obvia. Así ocurre a mi juicio, por ejemplo, respecto de los siguientes documentos aportados por la defensa:

“9.- Oficio N 336, de 08 de marzo de 2006 del señor Decano de la Facultad de Medicina de la Universidad de Chile, respecto del doctor Sergio Canals, que señala que éste ingresó al Programa de Psiquiatría Infantil, pero que no rindió el examen, requisito indispensable para optar al título de especialista. (letra c) $\mathrm{n}^{\circ} 12$ del auto de apertura)

Este documento será desestimado, porque el doctor Canals nunca negó ese hecho y reconoció en el juicio que no rindió el examen final en el programa de Especialistas de Psiquiatría Infantil, porque no se exigía en su época, agregando que aquello no le impedía dedicarse a atender pacientes infanto juveniles. Asimismo, si la defensa pretendía con ese documento, cuestionar la idoneidad del perito debió haberlo hecho valer en la oportunidad en que Canals declaró o al menos haber expresado la defensa, durante su incorporación por lectura resumida, lo que pretendía acreditar o desmerecer con ello. 
10.- Copia de una anamnesis, extendida por la Clínica Alemana, que da cuenta de atención efectuada por la pediatra doctora Cecilia Álvarez G. al menor XXX (letra c) $\mathrm{n}^{\circ} 17$ del auto de apertura). En él se da cuenta de una atención, de fecha veinte de julio del dos mil cinco, donde figura un diagnóstico de bronquitis aguda prob. Viral, y se describe como hechos relevantes una "enuresis nocturna hace dos noches, enfrenta hace dos semanas cambio de colegio y embarazo de la mamá de segundo matrimonio".

Este documento será desestimado porque solo da cuenta de un cuadro de bronquitis del niño, no pudiendo estos jueces darle valor a las conclusiones contenidas en ese informe, porque la profesional que lo extendió no declaró en el juicio oral como para haber ilustrado a estas sentenciadoras sobre el alcance de ese diagnóstico”.

Este análisis del último defecto atribuido a la sentencia de juicio oral confirma, a mi juicio, la imagen que se perfilaba al comienzo: la de una sentencia de nuestro máximo tribunal que no articula una justificación suficiente de su decisión de anular por falta de fundamentación y que no parece, por ello, tomar todo lo en serio que debiera la gravedad de esa decisión y la complejidad de su rol como garante de la racionalidad en la valoración de la prueba. El voto disidente del abogado integrante Domingo Hernández entrevé, en cambio, los dos puntos con lucidez cuando se refiere a la insuficiencia de "la sola mención genérica de estos elementos inherentes a la sana crítica, sin la debida especificación en cada caso" para "configurar un vicio de nulidad, con las consecuencias que de ello se derivan", y a la necesidad de preservar "el rigor en el análisis de la causal invocada y el imperativo de no desvirtuar el sentido y el alcance de este arbitrio" (consideración tercera). 